CLINICAL STUDY

\title{
Effects of growth environments and two environmental endocrine disruptors on children with idiopathic precocious puberty
}

\author{
Fang Deng ${ }^{1,2}$, Fang-biao Tao ${ }^{2}$, De-yun $\mathrm{Liu}^{3}$, Yuan-yuan $\mathrm{Xu}^{2}$, Jia-hu $\mathrm{Hao}^{2}$, Ying $\mathrm{Sun}^{2}$ and $\mathrm{Pu}-\mathrm{yu} \mathrm{Su}^{2}$ \\ ${ }^{1}$ Department of Pediatrics, First Affiliated Hospital, Anhui Medical University, Hefei, China, ${ }^{2}$ Anhui Provincial Key Laboratory of Population Health and \\ Aristogenics, Department of Maternal and Child Health, School of Public Health, Anhui Medical University, 81 Mei Shan Road, Hefei 230032, China \\ and ${ }^{3}$ Department of Pediatrics, Second Affiliated Hospital, Anhui Medical University, Hefei, China \\ (Correspondence should be addressed to F-b Tao; Email: fbtao@126.com)
}

\begin{abstract}
Objective: The incidence of idiopathic precocious puberty (IPP) might have an increasing trend. But the causes and risk factors of IPP are unknown. The objective of our study is to evaluate the effects of growth environments and two environmental endocrine disruptors (EDCs), zearalenone (ZEA), and 1,1-dichloro-2,2, bisethylene ( $p, p^{\prime}$-DDE), on patients with IPP.

Design: Case-control study.

Methods: The study consisted of 78 IPP patients at diagnosis and 100 control children matched for age and sex. A questionnaire was designed to collect data on growth environments, and serum ZEA and $p, p^{\prime}$-DDE were tested in all subjects. We analyzed data on growth environments, two EDCs, and biological interaction between growth environments and EDCs.

Results: In growth environments, small for gestational age, maternal physical disease during pregnancy, early maternal menarche, early puberty of same-degree relatives, and father's absence in 4- to 6-year olds were risk factors for children with IPP $(P<0.05)$. Serum ZEA concentration, ZEA, and $p, p^{\prime}$-DDEpositive rates in the IPP group were significantly higher than those in the control group $(P<0.05)$. There was a biological interaction between growth environments and ZEA (relative excess risk due to interaction $=34.562$, attributable proportion due to interaction $=0.745$, synergy index $=4.193$ ). Conclusions: Results suggest possible effects of growth environments and two EDCs on the development of IPP. In addition, growth environments and ZEA have biological interaction that might increase the risk of developing IPP.
\end{abstract}

European Journal of Endocrinology 166 803-809

\section{Introduction}

Idiopathic precocious puberty (IPP) is the result of premature reactivation of the hypothalamic-pituitarygonadal (HPG) axis, not related to intracranial pathology. This axis is first activated during infancy, when there is a physiological postnatal surge of gonadotropins designated as the 'mini-puberty' of infancy. In female infants, the gonadotropin surge is FSH predominant and peaks at about 3-6 months of life. Thereafter, gonadotropin levels decrease to prepubertal levels because of the increasing sensitivity of the hypothalamus and pituitary to the very low levels of circulating estrogens and because of the development of endogenous mechanisms in the $\mathrm{CN}$ that suppress the HPG axis. Puberty is initiated when this suppression is released. The mechanisms responsible for the suppression and subsequent activation of the HPG axis involve neuronal input to the hypothalamic gonadotrophinreleasing hormone pulse generator (1). However, the primary timing mechanism that initiates the activation and thus triggers puberty is unknown (2).

Precocious puberty is defined as the development of sex characteristics before the age of 8 years in girls and 9 years in boys. From the late 19th century to the mid20th century, a gradual decline in age at puberty has been reported in girls (3). In some developed countries, the ages of 7 years for white girls and 6 years for black girls have been proposed to determine precocious sexual maturation (4). But the causes of early puberty and IPP are still unclear.

Many studies have assessed the causes and risk factors of IPP. In addition to the genetic, ethnic, and pediatric obesity explanations for the earlier onset of sexual maturation $(5,6)$, other broad theories have been proposed. These include exposure to environmental toxins that disrupt endocrine function (7), psychosocial stress (8), and possible history of familial precocious puberty or adoption (9, 10). 1,1-Dichloro-2,2, bisethylene $\left(p, p^{\prime}\right.$-DDE) is the degradation product of DDT (a kind of 
organochlorine pesticide). DDT has been banned in China for almost 30 years, but its pollution to soil continues to exist. $p, p^{\prime}$-DDE can be the marker of early-life exposure to DDT. Zearalenone (ZEA) exists widely in mildewinfected cereal crops and dairy products. ZEA contamination is reported in almost all the food and food raw materials across the world. There are few reports about the hazard of ZEA to humans. The two environmental endocrine disruptors (EDCs) have estrogen-like effects and can interfere with children's puberty development.

In order to evaluate the risk factors of IPP, we analyzed data on growth environments and two EDCs, ZEA and $p, p^{\prime}$-DDE, in 78 IPP patients and 100 controls. The effects of biological interaction between growth environments and EDCs on IPP were also analyzed.

\section{Subjects and methods}

\section{Study subjects}

We studied 78 patients with IPP who were evaluated at the Endocrinology Clinic of First Affiliated Hospital of Anhui Medical University from January 1, 2009 to December 31, 2010. All patients had to meet all of the following criteria: i) onset of breast development before 8 years or menarche before 10 years in girls and testicular enlargement before the age of 9 years in boys; ii) $\mathrm{LH}$ peak $>5 \mathrm{IU} / \mathrm{l}$ and peak LH/FSH ratio $>0.6$ after LH-releasing hormone (LHRH) stimulation test (immunochemiluminometric assay, $100 \mu \mathrm{g} / \mathrm{m}^{2}$ ); iii) ovarian volume $>1 \mathrm{ml}$ and diameter of follicles $>4 \mathrm{~mm}$ or testicular volume $>4 \mathrm{ml}$ at ultrasound; and iv) no evidence of hypothalamic-pituitary organic lesions at magnetic resonance imaging $(10,11,12)$. All patients underwent abdominal ultrasonography to exclude adrenal disease and radiography of the left hand and wrist for bone age determination. One hundred healthy children matched for age and sex with no secondary sex characteristics were recruited as control subjects, some of whom were the children who went to see the doctor for a health checkup and some were pupils. Data on the distribution of sex and age characteristics between the two groups are listed in Table 1. The study protocol was approved by the Ethics Review Board of Anhui Medical University, and written consent was obtained from all subjects.

Table 1 Comparisons of subjects' sex and age characteristics.

\begin{tabular}{lllrr}
\hline & IPP & Control & \multicolumn{1}{c}{$\chi^{2} / \boldsymbol{Z}$} & $\boldsymbol{P}$ value \\
\hline Sex $(\mathrm{F} / \mathrm{M})$ & $76 / 2$ & $99 / 1$ & 0.647 & 0.582 \\
Age $(\bar{x} \pm s)$ & $6.64 \pm 2.77$ & $6.81 \pm 2.47$ & -0.116 & 0.908 \\
$\begin{array}{l}\text { Distribution of age, } \\
\text { years }(n ; \%)\end{array}$ & & & 3.372 & 0.338 \\
$<3$ & $14(17.9)$ & $16(16.0)$ & & \\
$3-7$ & $12(15.4)$ & $11(11.0)$ & & \\
$7-9$ & $42(53.8)$ & $66(66.0)$ & & \\
$\geq 9$ & $10(12.8)$ & $7(7.0)$ & & \\
\hline
\end{tabular}

\section{Investigation of growth environments}

All patients were evaluated at diagnosis. Data on growth environments were collected through questionnaires.

The height and weight of each subject were measured at diagnosis and body mass index (BMI (weight/height $\left.{ }^{2}\right)$ ) was calculated. Data on birth length, weight, and gestational age (GA) were collected. Children were defined as small for GA (SGA) if their birth weight was less than the 10th centile for GA. Prematurity was defined as a GA $<37$ weeks. Subjects' peak period of height and weight growth was investigated. Information regarding their peak growth was elicited by asking: How old were you when you had your peak growth of height/weight? Response alternatives were as follows: before 1 year/between ages 2 and 3/between ages 3 and 5/between ages 5 and 8/after age 8/always short (thin) compared with other children of same age/always high (fat) compared with other children of same age/normal compared with other children of same age.

Participants reported their registered residence (rural, suburban, urban), household structure (only child, more than one child, adopted child (yes, no), family economic status (above average, medium, below average), and diet habits (prefer meat, prefer vegetables, balanced diet). The proportion of time that the mother and/or father was living at home (parents' company) during the three periods of childhood (before 3 years, between ages 4 and 6 years, and after 6 years) was investigated. Response alternatives were as follows: less than half, half and above, and no company.

Information on maternal health including physical diseases and psychopathological symptoms during pregnancy was collected (yes, 1; no, 2). If participants had some maternal physical disease and/or psychological trauma (for example, the illness or death of a family member, working pressure, fortune loss, and poor family ties), they detail was clarified. Data on maternal menarche age and early puberty of samedegree relatives (yes, no) were also collected. Maternal menarche age was divided into groups of $\leq 12$ years and $>12$ years.

\section{Laboratory analyses}

At the first evaluation, each subject provided a nonfasting blood sample. The serum fractions were frozen at $-80{ }^{\circ} \mathrm{C}$ until extraction. Serum ZEA and $p, p^{\prime}$-DDE were tested.

Gas chromatographic analyses of the serum extracts with the use of electron capture detection and capillary columns of different polarity were used to analyze serum $p, p^{\prime}$-DDE of all samples. Standards of $p, p^{\prime}$-DDE (Accustandard, New Haven, CT, USA) were purchased. Quantitation was based on the response factor of each analyte relative to an internal standard. The coefficient 
of recovery of serum $p, p^{\prime}$-DDE was 54.923-73.938\%. The within-day and between-day relative s.D. was $<15 \%$. The method detection limit for $p, p^{\prime}$-DDE was $0.180 \mathrm{ng} / \mathrm{ml}$ (13).

Enzyme immunoassay was used for analyses of all samples. Standards of ZEA (R-Biopharm AG, Darmstadt, Germany) were purchased. Serum $(0.5 \mathrm{ml})$ was purified by C18 column (R-Biopharm AG). Test procedure was followed according to the manufacturer's instructions. The absorbency of the sample was used for the quantitative analysis. The absorbency is inversely proportional to the ZEA concentration in the sample. Qualitative analysis was also evaluated according to the absorbency of the sample compared with that of the concentration of 0 PPT of standard solution.

\section{Analysis of biological interaction between growth environments and EDCs}

Biological interaction of risk factors was calculated according to the method set up by Andersson (14). Subjects exposed to risk factors of growth environments were set as the positive group of growth environments. Subjects with elevated serum concentration of EDCs were set as the positive group of EDCs. The degree of biological interaction between growth environments and EDCs is measured as the deviation from additivity and not as deviation from multiplicativity. A logistic regression model according to whether the subject has the above two risk factors was defined in order to produce the output that is needed for the assessment of biological interaction. The covariance matrix of two risk factors was also calculated in multinomial logistic regression of Statistical Package for the Social Sciences (SPSS Inc., Chicago. IL, USA). An Excel spreadsheet based on the results from the logistic regression model and covariance matrix was used to calculate the indices of biological interaction and the corresponding confidence intervals (CIs). The Excel spreadsheet is available online: www.epinet.se. Three measures of biological interaction were presented: the relative excess risk due to interaction (RERI); the attributable proportion due to interaction (AP); and the synergy index (S). If there is biological interaction between the two factors, CIs of RERI and AP should be $>0$ and $S>1$.

\section{Statistical analysis}

Continuous data were described as means and s.D.s (mean \pm s.D.); categorical variables were expressed as cases or percentages. The statistical analysis of the data between group comparisons of categorical data parameters was performed using the $\chi^{2}$ test, and comparisons of continuous data were done with the independent samples $t$-test. A multivariate logistic regression model using the forward stepwise method was applied to evaluate the relationship between IPP and growth environments. The level of significance was set at $P<0.05$. SPSS Software (version 17.0) was used for all statistical analyses.

\section{Results \\ Descriptive characteristics of growth environments}

Relative to the control, the rates of preterm birth, SGA, maternal physical diseases and psychological traumas during pregnancy, better family economic condition, rural life, adoption, early maternal menarche $(\leq 12$ years), early puberty of same-degree relatives, and less company of the father during all of childhood were significantly high in IPP patients (Table 2). In the IPP group, two children could not provide GA because they were adopted. Five patients and four patients in the IPP group did not report maternal psychological trauma and physical disease during pregnancy respectively. Among maternal physical disease during pregnancy, acute upper respiration infection was the most familiar one and reported by 11 subjects. The mean age of maternal menarche in IPP group was significantly lower than that in control group $(13.33 \pm 1.59$ vs $14.02 \pm 1.37, P=0.004)$.

There was no significant difference between the two groups in BMI, birth length and weight, household structure, diet habits, and mother's company in all periods of childhood $(P>0.05)$.

There was no significant difference in the peak of weight growth between two groups at every stage of childhood. In IPP group, the proportion of peak height growth after 5 years was significantly higher than that in the control, but there was no difference before 5 years.

In the binary logistic regression model, IPP was set as a dependent variable, and all the above 12 variables that were significantly different between IPP and control groups were added to the model as independent variables. The indicator of every independent variable was set as follows: preterm birth (no), SGA (no), maternal physical disease (no) and psychological trauma (no) during pregnancy, family economic status (medium), registered residence (urban), adoption (no), maternal menarche age ( $>12$ years), early puberty of same-degree relatives (no), and father's company in three periods of childhood (half and above). In the results of multivariate analysis, only SGA, physical disease during pregnancy, early maternal menarche, early puberty of same-degree relatives, and less father's company between 4-6 years entered the model. As Table 3 shows, the five variables were risk factors of IPP.

\section{Laboratory results}

There was no difference in the concentration of $p, p^{\prime}$-DDE between the two groups. The concentration of $p, p^{\prime}$-DDE in one patient in the IPP group and ten patients in the 
Table 2 Comparisons of growth environments between two groups.

\begin{tabular}{|c|c|c|c|}
\hline & IPP & Control & $\chi^{2} / P$ \\
\hline \multicolumn{3}{|l|}{ Prematurity } & $4.375 / 0.036$ \\
\hline Yes & $8(10.5 \%)$ & $2(2.0 \%)$ & \\
\hline No & $68(89.5 \%)$ & $98(98 \%)$ & \\
\hline \multicolumn{3}{|l|}{ SGA } & $4.246 / 0.039$ \\
\hline Yes & $12(15.4 \%)$ & $6(6.0 \%)$ & \\
\hline No & $66(84.6 \%)$ & $94(94 \%)$ & \\
\hline \multicolumn{3}{|c|}{ Registered residence } & $6.715 / 0.035$ \\
\hline Rural & $15(19.2 \%)$ & $13(13.0 \%)$ & \\
\hline Suburb & $10(12.8 \%)$ & $4(4.0 \%)$ & \\
\hline Urban & $53(68.0 \%)$ & $83(83.0 \%)$ & \\
\hline \multicolumn{3}{|c|}{ Family economic status } & $6.114 / 0.047$ \\
\hline Above average & $16(20.5 \%)$ & $8(8.0 \%)$ & \\
\hline Medium & $50(64.1 \%)$ & $77(77.0 \%)$ & \\
\hline Lower average & $12(15.4 \%)$ & $15(15.0 \%)$ & \\
\hline \multicolumn{3}{|l|}{ Adopted child } & $7.298 / 0.007$ \\
\hline Yes & $9(11.5 \%)$ & $1(1.0 \%)$ & \\
\hline No & $69(88.5 \%)$ & $99(99.0 \%)$ & \\
\hline \multicolumn{4}{|l|}{ Maternal status } \\
\hline Physical disease & & & $6.419 / 0.011$ \\
\hline Yes & 19 (25.7\%) & $11(11.0 \%)$ & \\
\hline No & 55 (74.3\%) & $89(89.0 \%)$ & \\
\hline \multicolumn{3}{|c|}{ Psychological trauma } & $4.032 / 0.045$ \\
\hline Yes & $10(13.7 \%)$ & $5.0 \%$ & \\
\hline No & $63(86.3 \%)$ & $95(95.0 \%)$ & \\
\hline \multicolumn{3}{|l|}{ Age at menarche } & $6.462 / 0.011$ \\
\hline$\leq 12$ years & $21(26.9 \%)$ & $12(12.0 \%)$ & \\
\hline$>12$ years & $57(73.1 \%)$ & $88(88.0 \%)$ & \\
\hline \multicolumn{3}{|c|}{$\begin{array}{l}\text { Early puberty of } \\
\text { same-degree relatives }\end{array}$} & $7.298 / 0.007$ \\
\hline No & $69(88.5 \%)$ & $99(99.0 \%)$ & \\
\hline Yes & $9(11.5 \%)$ & $1(1.0 \%)$ & \\
\hline \multicolumn{4}{|l|}{ Company of father } \\
\hline \multicolumn{3}{|l|}{ Before 3 years } & $6.844 / 0.033$ \\
\hline Half and above & $31(39.7 \%)$ & $59(59.0 \%)$ & \\
\hline Less than half & $44(56.4 \%)$ & $37(37.0 \%)$ & \\
\hline No company & $3(3.9 \%)$ & $4(4.0 \%)$ & \\
\hline \multicolumn{3}{|c|}{ Between 4 and 6 years } & $17.734 / 0.000$ \\
\hline Half and above & $24(38.7 \%)$ & $60(73.2 \%)$ & \\
\hline Less than half & $35(56.5 \%)$ & $19(23.2 \%)$ & \\
\hline No company & $3(4.8 \%)$ & $3(3.7 \%)$ & \\
\hline \multicolumn{3}{|l|}{ After 6 years } & $13.829 / 0.001$ \\
\hline Half and above & $24(44.4 \%)$ & $60(75.9 \%)$ & \\
\hline Less than half & $25(46.3 \%)$ & $15(19.0 \%)$ & \\
\hline No company & $5(9.3 \%)$ & $4(5.1 \%)$ & \\
\hline
\end{tabular}

control group was below $0.180 \mathrm{ng} / \mathrm{ml}$. The positive rate of ZEA in the IPP group was significantly higher than that in the control. The absorbency in the IPP group was significantly lower than that in the control, so the concentration in IPP group was significantly higher than the control (Table 4).

\section{Biological interaction of growth environments and EDCs}

Subjects with one or more of the above five risk factors of growth environments were set as the positive group of growth environments. Subjects with a positive result from the qualitative test of ZEA was set as the positive group of ZEA. A new variable 'group’ was set (Table 5). We also defined those who were unexposed to both of the growth environments and ZEA as reference category, i.e. odds ratio $=1$. The three relative risk estimates and the corresponding covariance matrix could be obtained from a logistic regression model. The RERI and AP for this interaction were 34.562 (95\% CI, $0.419-68.704)$ and 0.745 (95\%CI, $0.426-1.064)$ respectively, and S was 4.193 (95\% CI, 1.106-15.900).

\section{Discussion}

In this study, we demonstrated an association between growth environments and IPP. We found that SGA, physical disease during pregnancy, early maternal menarche, early puberty of same-degree relatives, and less company of the father between 4-6 years were the risk factors of IPP. Higher serum ZEA concentration was found in IPP patients compared with the controls, and higher positive rates of ZEA and $p, p^{\prime}$-DDE were associated with greater risk of IPP. There was a biological interaction between growth environments and ZEA.

Genetic factors play a fundamental role in the timing of pubertal onset. Several mutations, such as GNRH1, GPR 54 (KISS1R), GNRHR, TAC3 (TAC2), and TACR3, have been identified in an increasing number of genes that influence the onset of puberty. Mutations of the genes encoding the kisspeptin and its receptor were recently found to be associated with central precocious puberty phenotype. An autosomal dominant GPR54 mutation, the substitution of proline for arginine at codon 386 (Arg386Pro), appears to be associated with central precocious puberty $(5,15)$. Of our patients, $26.9 \%$ had a history of maternal early menarche and $11.5 \%$ had early puberty of same-degree relatives. In the multivariate logistic regression model, early maternal menarche and early puberty of same-degree relatives were risk factors of IPP. The causes of IPP might be associated with heredity and environment

Table 3 Results of regression analysis of growth environments and IPP.

\begin{tabular}{|c|c|c|c|c|c|}
\hline & $\beta$ & S.E.M. & Wald & $\boldsymbol{P}$ & OR $(95 \% \mathrm{Cl})$ \\
\hline Physical disease during pregnancy & 1.747 & 0.609 & 8.225 & 0.004 & $5.737(1.739-18.928)$ \\
\hline SGA & 1.499 & 0.761 & 3.879 & 0.049 & $4.476(1.007-19.884)$ \\
\hline Early maternal menarche ( $\leq 12$ years) & 1.711 & 0.518 & 10.912 & 0.001 & $5.537(2.006-15.286)$ \\
\hline Early puberty of same-degree relatives & 2.471 & 1.157 & 4.563 & 0.033 & $11.830(1.226-114.149)$ \\
\hline $\begin{array}{l}\text { Company of father in } 4-6 \text { years } \\
\text { (less than half) }\end{array}$ & 1.292 & 0.453 & 8.120 & 0.004 & $3.640(1.497-8.850)$ \\
\hline
\end{tabular}

$\mathrm{Cl}$, confidence interval; OR, odds ratio. 
Table 4 Comparison of results of $p, p^{\prime}$-DDE and ZEA between two groups.

\begin{tabular}{|c|c|c|c|c|}
\hline & \multicolumn{2}{|c|}{$p, p^{\prime}-\mathrm{DDE}$} & \multicolumn{2}{|c|}{ ZEA } \\
\hline & Positive (\%) & $\begin{array}{l}\text { Concentration } \\
(\bar{x} \pm s)\end{array}$ & Positive (\%) & $\begin{array}{l}\text { Absorbency } \\
(\bar{x} \pm s)\end{array}$ \\
\hline IPP & 77 (98.7\%) & $2.35 \pm 2.00$ & 29 (37.2\%) & $1.81 \pm 0.19$ \\
\hline Control & 90 (90.0\%) & $2.28 \pm 2.00$ & $6(6.0 \%)$ & $1.96 \pm 0.14$ \\
\hline$\chi^{2} / t$ & 4.339 & 0.211 & 26.968 & -3.081 \\
\hline$P$ & 0.037 & 0.833 & 0.000 & 0.003 \\
\hline
\end{tabular}

factors. Pigneur et al. (10) evaluated the frequency of familial factors in patients with IPP and found that almost half of patients had a family history of early puberty, mainly in the mothers and sisters. BMI was greater in the familial form than in the nonfamilial form, and this suggested that familial obesity might contribute to IPP. de Vries et al. (16) studied 156 patients with IPP, which was familial in 43 (42 girls and one boy; $27.5 \%$ ). The familial group was characterized by a significantly lower maternal age at menarche than the sporadic group. Segregation analysis was used to study the mode of inheritance, and the results suggested autosomal dominant transmission with incomplete, sex-dependent penetrance. The high prevalence of familial cases suggests that when a child is diagnosed with IPP, a careful, detailed inquiry of the extended family regarding precocious puberty should be sought. Parents should be notified of the possibility of the disorder occurring in their other children.

Higher prevalence of the father's absence was found in IPP patients. Similar results were found in other studies. In both men and women, the father's absence at age 14 predicted an earlier age of puberty (e.g. early menarche or voice change). There was little evidence that mother's absence, independent of a the father's absence, was related to early puberty in either men or women (17). The longer duration of the father's absence, the earlier menarche of their daughter (18). Those results suggest that psychosocial factors may affect growth and development in adolescents. The mechanism is probably that stress associated with the father's absence alters hormones (e.g. cortisol), which precipitates an early puberty. Another theory is that children are attuned to certain environmental cues (e.g. father's absence) and may adopt an 'unrestricted' mating/life history strategy (e.g. early puberty and mating) if they perceive that their adult environments are likely to be unpredictable and unstable (19). However, if these theories are correct, it is not clear why a mother's absence might not have a similar stress effect on pubertal timing. Other explanations were also stated, for example, a gene(s) predisposes a father to various impulsive behaviors (e.g. family abandonment) and both their daughters and sons to early puberty (20). This study adds confidence that the relationship between the father's absence and early puberty in women is generalizable. The exact mechanism of this relationship is unknown. Some studies tested for a mediator (e.g. BMI) affecting the father's absence/puberty relationship (21). This needs to be confirmed with more data.

There are many reports about the relationship between adopted or immigrant children and developing IPP (9, 22). Soriano et al. (23) reported the data on prevalence and incidence of CPP in Spain and showed that adoption, either domestic or foreign, is a risk factor for developing central precocious puberty (CPP). The mechanism explaining the relationship between adoption and CPP remains unknown, and current speculation includes the influence of racial, emotional, and environmental factors. There are no international adopted children in China, but there are domestic adopted children. The proportion of domestic adoption was significantly higher in the IPP group than in the control in our study, but in multivariate logistic regression analysis, adoption was not the risk factor of IPP.

The weight-of-the-evidence evaluation of human and animal studies suggest that EDCs, particularly the estrogen mimics and antiandrogens, are an important factor associated with a secular trend toward earlier breast development onset and menarche (24). Many EDCs are estrogen agonists and/or androgen antagonists. Thus, they can dysregulate the HPG axis potentially affecting human puberty timing. ZEA is a nonsteroidal mycotoxin produced by Fusarium species on several grains. Despite its low acute toxicity and carcinogenicity, ZEA exhibits estrogenic and anabolic properties in several animal species. ZEA food contamination is caused either by direct contamination of grains, fruits, and products based on them or by 'carry-over' of mycotoxins in animal tissues, milk, and eggs after intake of contaminated feedstuff. From 1978 to 1984, a great epidemic of premature thelarche and precocious puberty occurred in Puerto Rico. To explain this condition, it was suggested that dairy and meat products could be contaminated with anabolic estrogens such as ZEA or $\alpha$-ZAL $(25,26)$. Massart et al. (27) studied the serum levels of ZEA in IPP patients and the controls. At diagnosis, six patients had higher serum ZEA levels than other subjects, and all these six patients came from the same area. By contrast, ZEA was not detected in patients from the other area or control subjects. At diagnosis, ZEA levels correlated with patient height and weight. So ZEA is suspected to be a triggering factor for IPP development in girls and may also represent a growth promoter in exposed patients.

Table 5 Results of two risk factors in logistic regression.

\begin{tabular}{llcll}
\hline $\begin{array}{l}\text { Growth } \\
\text { environments }\end{array}$ & ZEA & Group & $\beta$ & OR (95\% Cl) \\
\hline 0 & 0 & 0 & - & 1.00 \\
+ & 0 & 1 & 1.383 & $3.986(1.849-8.593)$ \\
0 & + & 2 & 2.179 & $8.833(2.281-34.208)$ \\
+ & + & 3 & 3.837 & $46.375(9.553-225.138)$ \\
\hline
\end{tabular}


In our study, higher serum ZEA concentration and higher positive rate of ZEA were found in IPP patients compared with controls. Patients with two risk factors, ZEA and growth environments, had greater risk of developing IPP. These data suggest a possible relationship between ZEA and IPP. Cohort studies should be carried out to clarify this relationship. Possible mechanism of effects of ZEA on IPP, and the dose, duration, and time period of exposure of ZEA should be studied.

The causes of IPP may involve many aspects. The most significant feature of this study is that we study the combined effects of growth environments and EDCs on IPP. Many studies evaluated the causes and risk factors of IPP, but to our knowledge, there were no studies devoted to studying the combined effects of many factors on IPP. The limitation of this study is the small sample size, which is associated with the low incidence of IPP. Another limitation is that we collected data on growth environments through questionnaires. Growth records can increase the credibility, but many subjects did not have records of their growth and developments.

In conclusion, this study suggests the possible effects of growth environments and two EDCs on the development of IPP. In addition, growth environments and ZEA have biological interaction, which might increase the risk of developing IPP.

\section{Declaration of interest}

The authors declare that there is no conflict of interest that could be perceived as prejudicing the impartiality of the research reported.

\section{Funding}

This study was financially supported by the Natural Science Foundation of China (grant number 81102145), Natural Science Foundation of Anhui Province (grant number KJ2010A163), and the Scientific and Technological Project of Anhui Province (grant number 11040606M168).

\section{References}

1 Terasawa E \& Fernandez DL. Neurobiological mechanisms of the onset of puberty in primates. Endocrine Reviews 2001 22 111-151. (doi:10.1210/er.22.1.111)

2 Grumbach MM. The neuroendocrinology of human puberty revisited. Hormone Research 200257 (Suppl 2) 2-14. (doi:10. 1159/000058094)

3 Euling SY, Herman-Giddens ME, Lee PA, Selevan SG, Juul A, Sørensen TI, Dunkel L, Himes JH, Teilmann G \& Swan SH. Examination of US puberty-timing data from 1940 to 1994 for secular trends: panel findings. Pediatrics $2008 \mathbf{1 2 1}$ (Suppl 3) S172-S191. (doi:10.1542/peds.2007-1813D)

4 Kaplowitz PB \& Oberfield SE. Reexamination of the age limit for defining when puberty is precocious in girls in the United States: implications for evaluation and treatment. Drug and Therapeutics and Executive Committees of the Lawson Wilkins Pediatric Endocrine Society. Pediatrics 1999104 936-941. (doi:10.1542/ peds.104.4.936)

5 Teles MG, Bianco SD, Brito VN, Trarbach EB, Kuohung W, Xu S, Seminara SB, Mendonca BB, Kaiser UB \& Latronico AC.
A GPR54-activating mutation in a patient with central precocious puberty. New England Journal of Medicine 2008358 709-715. (doi:10.1056/NEJMoa073443)

6 Shalitin S \& Phillip M. Role of obesity and leptin in the pubertal process and pubertal growth: a review. International Journal of Obesity 200327 869-874. (doi:10.1038/sj.ijo.0802328)

7 Mouritsen A, Aksglaede L, Sørensen K, Mogensen SS, Leffers H, Main KM, Frederiksen H, Andersson AM, Skakkebaek NE \& Juul A. Hypothesis: exposure to endocrine-disrupting chemicals may interfere with timing of puberty. International Journal of Andrology 201033 346-359. (doi:10.1111/j.1365-2605.2010.01051.x)

8 Toromanović A \& Tahirović H. Menarcheal age of girls from dysfunctional families. Bosnian Journal of Basic Medical Sciences $200445-6$.

9 Teilmann G, Boas M, Petersen JH, Main KM, Gormsen M, Damgaard K, Brocks V, Skakkebaek NE \& Jensen TK. Early pituitary-gonadal activation before clinical signs of puberty in 5- to 8-year-old adopted girls: a study of 99 foreign adopted girls and 93 controls. Journal of Clinical Endocrinology and Metabolism 200792 2538-2544. (doi:10.1210/jc.2006-2096)

10 Pigneur B, Trivin C \& Brauner R. Idiopathic central precocious puberty in 28 boys. Medical Science Monitor 200814 CR10-CR14.

11 Subspecialty Group of Endocrinology, Hereditary and Metabolic Diseases, Society of Pediatrics, Chinese Medical Association. Guidelines for diagnosis and treatment of central (true) precocious puberty. Zhonghua Er Ke Za Zhi 200745 426-427.

12 Pasquino AM, Pucarelli I, Accardo F, Demiraj V, Segni M \& Di Nardo R. Long-term observation of 87 girls with idiopathic central precocious puberty treated with gonadotropin-releasing hormone analogs: impact on adult height, body mass index, bone mineral content, and reproductive function. Journal of Clinical Endocrinology and Metabolism 200893 190-195. (doi:10.1210/jc.2007-1216)

13 Ouyang F, Perry MJ, Venners SA, Chen C, Wang B, Yang F, Fang Z, Zang T, Wang L, Xu X \& Wang X. Serum DDT, age at menarche, and abnormal menstrual cycle length. Occupational and Environmental Medicine 200562 878-884. (doi:10.1136/oem.2005.020248)

14 Andersson T, Alfredsson L, Källberg H, Zdravkovic S \& Ahlbom A. Calculating measures of biological interaction. European Journal of Epidemiology 200520 575-579. (doi:10.1007/s10654-0057835-x)

15 Silveira LF, Trarbach EB \& Latronico AC. Genetics basis for GnRHdependent pubertal disorders in humans. Molecular and Cellular Endocrinology 2010324 30-38. (doi:10.1016/j.mce.2010.02.023)

16 de Vries L, Kauschansky A, Shohat M \& Phillip M. Familial central precocious puberty suggests autosomal dominant inheritance. Journal of Clinical Endocrinology and Metabolism 200489 1794-1800. (doi:10.1210/jc.2003-030361)

17 Bogaert AF. Age at puberty and father absence in a national probability sample. Journal of Adolescence $2005 \mathbf{2 8} 541-546$. (doi:10.1016/j.adolescence.2004.10.008)

18 Moffitt TE, Caspi A, Belsky J \& Silva PA. Childhood experience and the onset of menarche: a test of a sociobiological model. Child Development 199263 47-58. (doi:10.2307/1130900)

19 Belsky J, Steinberg L \& Draper P. Childhood experience, interpersonal development, and reproductive strategy: and evolutionary theory of socialization. Child Development 199162 647-670. (doi:10.2307/1131166)

20 Comings DE, Muhleman D, Johnson JP \& MacMurray JP. Parent-daughter transmission of the androgen receptor gene as an explanation of the effect of father absence on age of menarche. Child Development 200273 1046-1051. (doi:10.1111/14678624.00456)

21 Bogaert AF. Menarche and father absence in a national probability sample. Journal of Biosocial Science $2008 \mathbf{4 0}$ 623-636. (doi:10. 1017/S0021932007002386)

22 Krstevska-Konstantinova M, Charlier C, Craen M, Du Caju M, Heinrichs C, de Beaufort C, Plomteux G \& Bourguignon JP. Sexual precocity after immigration from developing countries to Belgium: evidence of previous exposure to organochlorine pesticides. Human Reproduction 200116 1020-1026. (doi:10.1093/hum$\mathrm{rep} / 16.5 .1020)$ 
23 Soriano-Guillén L, Corripio R, Labarta JI, Cañete R, CastroFeijóo L, Espino R \& Argente J. Central precocious puberty in children living in Spain: incidence, prevalence, and influence of adoption and immigration. Journal of Clinical Endocrinology and Metabolism 201095 4305-4313. (doi:10.1210/jc.2010-1025)

24 Euling SY, Selevan SG, Pescovitz OH \& Skakkebaek NE. Role of environmental factors in the timing of puberty. Pediatrics 2008 121 (Suppl 3) S167-S171. (doi:10.1542/peds.2007-1813C)

25 Larriuz-Serrano MC, Pérez-Cardona CM, Ramos-Valencia G \& Bourdony CJ. Natural history and incidence of premature thelarche in Puerto Rican girls aged 6 months to 8 years diagnosed between 1990 and 1995. Puerto Rico Health Sciences Journal $20012013-18$.
26 Massart F \& Saggese G. Oestrogenic mycotoxin exposures and precocious pubertal development. International Journal of Andrology 201033 369-376. (doi:10.1111/j.1365-2605.2009.01009.x)

27 Massart F, Meucci V, Saggese G \& Soldani G. High growth rate of girls with precocious puberty exposed to estrogenic mycotoxins. Journal of Pediatrics 2008152 690-695. (doi:10.1016/j.jpeds. 2007.10.020)

Received 8 October 2011

Revised version received 21 January 2012

Accepted 8 February 2012 